\title{
BRIKET BAHAN BAKAR DARI AMPAS TEH DENGAN PEREKAT LEM KANJI
}

\section{Fuel Briquettes from Waste Tea With Adhesive Kanji Glue}

\author{
Budhi Indrawijaya *, Lili Mursida, Nita Dwi Andini \\ Program Studi Teknik Kimia, Fakultas Teknik, Universitas Pamulang 45363 Pamulang \\ Jalan Surya Kencana No. 1 Pamulang Kota Tangerang Selatan, Banten 15417 \\ *Email : budhi.indrawijaya@gmail.com
}

\begin{abstract}
ABSTRAK
Limbah ampas teh banyak dihasilkan dari perusahaan yang berkembang dalam bidang pengolahan minuman teh ready to drink. Ampas teh yang merupakan hasil dari ekstraksi biasanya hanya dibuang begitu saja, atau paling tidak digunakan untuk pembuatan pupuk organik. Sebenarnya ampas teh dapat dijadikan alternatif lain salah satunya yakni dapat digunakan sebagai pembuatan bahan bakar dengan cara dibuat menjadi briket bahan bakar. Proses yang dilakukan seperti pengeringan ampas teh dapat dikeringkan di bawah sinar matahari dan juga dibakar di dalam suatu wadah, kemudian digiling dan disaring dan dicampurkan dengan lem kanji. Campuran kemudian dipadatkan secara manual agar proses dapat diaplikasikan dalam keseharian (rumah tangga). Briket ini dikeringkan bisa dengan cara dijemur atau di dalam oven suhu $\pm 1100 \mathrm{C}$ selama 1 jam. Penelitian ini menghasilkan briket dengan kadar air yang rendah sebesar 4,69\%, kadar abu terendah sebesar 2,1\%, dan nilai kalor yang paling mendekati standar sebesar $3960,69 \mathrm{cal} / \mathrm{g}$.
\end{abstract}

Kata kunci: briket, kadar air, kadar abu, bom kalori

\begin{abstract}
Waste of tea pulp is produced from companies that are developing in the field of processing ready-to-drink tea drinks. Tea pulp which is the result of extraction is usually just thrown away, or at least used for making organic fertilizers. Actually, tea pulp can be used as an alternative, one of that it can be used as the manufacture of fuel by making it into fuel briquettes. The process carried out such as drying tea pulp can be dried in the sun and also burned in a container, then milled and filtered and mixed with starch glue. The mixture is then compacted manually so that the process can be applied in daily life (household). This briquette can be dried by drying or in an oven temperature of $\pm 110^{\circ} \mathrm{C}$ for an hour. This research produced briquettes with a low water content of $4.69 \%$, the lowest ash content of $2.1 \%$, and the closest heating value to a standard of $3960.69 \mathrm{cal} / \mathrm{g}$.
\end{abstract}

Keywords: briquettes, water content, ash content, calorie bombs

\section{PENDAHULUAN}

Kebutuhan akan energi di Indonesia semakin hari semakin meningkat. Untuk menyeimbangkan permintaan dan suplai maka dicari energi alternatif untuk mengimbangi semakin berkurangnya cadangan sampel minyak bumi dan gas LPG.
Bahan bakar alternatif bisa dibuat dari berbagai bahan-bahan yang berasal dari sampah organik rumah tangga, kayu dan lainnya yang bersifat kontinyu dan dapat diperbaharui. Indonesia merupakan negara yang kaya akan keanekaragaman hayatinya. Salah satu keanekaragaman hayati yang dapat dimanfaatkan dalam bidang 
perindustrian dan rumah tangga yakni ampas teh dan tepung kanji.

Sebagian masyarakat Indonesia sangat menggemari teh sebagai minuman yang biasa dikonsumsi. Selain bau yang harum teh juga memiliki rasa yang enak. Teh juga dapat disajikan dalam bentuk hangat untuk menghangatkan tubuh atau bisa juga disajikan dalam keadaan dingin sesuai selera. Setelah disajikan, ampas teh biasanya langsung dibuang. Tapi sebetulnya ampas teh dapat di manfaatkan untuk tumbuhan yaitu dapat dijadikan sebagai pupuk, namun ampas teh jika diarangkan juga dapat dibuat menjadi bahan bakar alternatif. Limbah rumah tangga ini bisa digunakan langsung tanpa diolah lagi.

Tepung kanji bahan dasarnya adalah dari singkong. Tidak hanya digunakan dalam bidang kuliner tetapi juga bisa digunakan sebagai bahan alternatif lain, yakni sebagai bahan perekat (lem kanji). Lem kanji sebagai bahan perekat yang dapat digabungkan dengan ampas teh memiliki sifat tidak berbau, tidak beracun, dan tidak berbahaya serta mudah didapatkan. Tepung kanji mengandung amilosa 28\% dan amilopektin $72 \%$.

Briket merupakan salah satu bahan bakar alternatif yang serupa dengan arang tetapi terbuat dari bahan non kayu. Banyak bahan-bahan yang dapat digunakan sebagai sampel pembuatan briket diantaranya adalah ampas kopi, ampas teh, sekam padi, jerami, batok kelapa, serbuk gergaji, dedaunan dan lain-lain.

\section{BAHAN DAN METODE}

Bahan yang digunakan dalam penelitian adalah ampas teh, bahan perekat tepung tapioka, air. Sementara alat-alat yang digunakan adalah timbangan digital, wadah untuk penimbangan bahan, pengaduk, wadah pengaduk, wadah untuk mencetak dan press briket, kompor, gelas ukur, blender, cawan porselen, penjepit, desikator, oven, tanur, bomb kalorimeter.

\section{Persiapan bahan baku}

Ampas teh diambil dari PT. Surya Lestari Abadi, di daerah Pondok Benda, Pamulang 2, Tangerang Selatan kemudian ampas teh dibersihkan dari kotoran dan material tidak berguna lainnya, selanjutnya ampas teh dikeringkan dengan cara dijemur di bawah sinar matahari selama \pm 1 bulan untuk mengurangi kadar air yang terkandung pada ampas teh tersebut. Ampas teh yang telah dikarbonisasi digiling dengan menggunakan mesin penggiling hingga berbentuk bubuk (powder).

\section{Proses karbonisasi}

$\begin{array}{clrr}\text { Ampas } & \text { teh yang } & \text { sudah } & \text { kering } \\ \text { dimasukan } & \text { kedalam } & \text { kaleng } & \text { atau }\end{array}$
penggorengan kemudian tutup rapat penggorengan dan kaleng untuk menghindari adanya udara masuk pada saat proses karbonisasi. Nyalakan kompor dan tunggu hingga ampas teh berbentuk seperti arang/agak mengering. Setelah itu matikan kompor saat ampas teh sudah berubah menjadi kering.

\section{Proses penghancuran ampas teh}

Proses penghancuran ampas teh menggunakan blender hingga ampas teh berubah menjadi serbuk yang cukup halus.

\section{Proses pembuatan lem kanji}

Timbang tepung kanji sebanyak 30 gram, kemudian larutkan dengan $300 \mathrm{ml}$ air selanjutnya dimasak di atas kompor dengan api kecil dan diaduk hingga mengental.

\section{Proses pencampuran ampas teh dan lem kanji}


Ditimbang ampas teh yang sudah menjadi serbuk sesuai komposisi yang sudah ditentukan dan timbang lem kanji yang sudah siap digunakan sesuai komposisi yang sudah ditentukan kemudian campurkan ampas teh dan lem kanji di dalam wadah, selanjutnya aduk dengan pengaduk hingga tercampur rata, jangan sampai ada gumpalan yang tidak rata.

\section{Proses pencetakan dan pengepressan}

Ampas teh dan lem kanji yang sudah tercampur rata dimasukkan ke dalam suatu wadah yang juga sebagai wadah pengepressan kemudian tekan dengan pengaduk dan diberikan tekanan menggunakan tangan dengan kuat, selanjutnya setelah padat dan kompak briket siap dikeluarkan dan dijemur kembali untuk menurunkan kadar air.

\section{Pengujian kadar air (moisture content)}

Menyiapkan peralatan dan bahan yang akan digunakan. Selanjutnya cawan porselen kosong dimasukkan ke dalam oven terlebih dahulu \pm 10 menit pada suhu $110^{\circ} \mathrm{C}$ untuk menghilangkan kandungan air pada cawan. Setelah itu cawan porselen dimasukkan dalam desikator. Kemudian bobot cawan kosong ditimbang. Selanjutnya sampel dimasukkan ke dalam cawan porselen dan dimasukkan ke dalam oven pada temperatur $110^{\circ} \mathrm{C}$ selama 4 jam. Setelah dipanaskan sampel dimasukkan ke dalam desikator untuk proses pendinginan dan penyerapan kadar air oleh silica gel. Berikutnya sampel ditimbang untuk mengetahui bobot cawan + sampel setelah pemanasan pertama. Kemudian dilanjutkan tahap berikutnya hingga mencapai bobot tetap, namun waktu di pemanasan dikurangi menjadi 1 jam. Persentase kadar air didapat dengan dihitung menggunakan standar ASTM D-3173-03 dengan persamaan sebagai berikut :

$$
\text { Kadar Air, } \%=\frac{a-b}{a} \times 100 \%
$$

Dimana :

$\mathrm{a}=$ Massa awal briket (gram)

$\mathrm{b}=$ Massa briket setelah pemanasan $110^{\circ} \mathrm{C}$ (gram)

\section{Pengujian kadar abu (ash content)}

Menyiapkan peralatan dan bahan yang akan digunakan. Kemudian cawan porselen kosong dimasukkan ke dalam oven terlebih dahulu \pm 10 menit pada suhu $110^{\circ} \mathrm{C}$ untuk menghilangkan kandungan air pada cawan. Setelah itu cawan porselen dimasukkan dalam desikator agar cawan tidak panas lagi. Selanjutnya cawan kosong ditimbang dan kemudian sampel dimasukkan ke dalam cawan porselen. Kemudian sampel dimasukkan ke dalam tanur pada suhu \pm $750^{\circ} \mathrm{C}$ untuk proses pembentukkan abu. Selanjutnya didinginkan di dalam desikator selama 15 menit kemudian ditimbang. Persentase kadar abu didapat dengan dihitung menggunakan standar ASTM D-3174-04 dengan persamaan sebagai berikut :

$$
\text { Kadar Abu\% }=\frac{b}{a} \times 100 \%
$$

Dimana :

$\mathrm{a}=$ berat sampel sebelum pemanasan (gram)

$\mathrm{b}=$ berat sampel sesudah pemanasan (gram)

\section{Pengujian Nilai Kalor}

Pada pengujian nilai kalor digunakan alat bomb kalorimeter digital, yang telah disetujui oleh ASTM/DIN yang dapat dengan cepat dan tepat menentukan nilai kalor dari bahan bakar baik yang berbentuk padat maupun cair. Caranya adalah sampel seberat 1 gram ditimbang, kemudian diletakkan pada cawan khusus bomb kalorimeter. Setelah itu 
sampel dimasukkan ke dalam vessel, kemudian tutup vessel dan masukkan gas oksigen sampai pada tekanan 28-30 bar. Selanjutnya temperatur sebelum dan sesudah pembakaran akan langsung terbaca dan hasil nilai kalor akan muncul di komputer.

\section{HASIL DAN PEMBAHASAN}

\section{Hasil pengujian}

Sampel ampas teh yang digunakan untuk penelitian ini didapatkan dari PT Surya Lestari Abadi yang berlokasi di Pamulang 2 Tangerang Selatan. Sampel yang diambil dari PT Surya Lestari Abadi sebanyak \pm 20 kg. Karena pembuatan sampel yang berulangulang maka dibutuhkan cukup banyak ampas teh untuk menemukan komposisi yang sempurna untuk menjadikan briket dengan kualitas yang baik.

Ampas teh pertama-tama harus dijemur kurang lebih selama 1 bulan, karena ampas teh yang diambil masih dalam keadaan basah dan masih mengandung banyak air. Tujuan dari dijemurnya ampas teh selama 1 bulan adalah agar kadar air dari ampas teh menurun drastis. Ampas teh juga harus dibakar di suatu wadah sehingga menjadi lebih kering sehingga ketika sudah jadi briket menjadi mudah dibakar. Dikarenakan penjemuran sudah dilakukan selama 1 bulan, maka waktu untuk pembakaran akan dikurangi, yang pada umumnya proses tersebut dilakukan dalam waktu \pm 10 jam, hal ini hanya membutuhan waktu \pm 1 jam.

\section{Pembahasan}

Kadar air (moisture content) dalam bahan bakar berhubungan erat dengan penyalaan awal bahan bakar, semakin tinggi moisture briket yang dihasilkan, maka akan semakin sulit penyalaan awal briket tersebut. Dari Tabel 1 dapat diketahui hasil pengujian analisis kadar air sampel briket ampas teh. Hasil pengujian memperlihatkan bahwa sampel nomor 4 (20 gram ampas teh dengan 15 gram lem kanji) memiliki nilai kadar air terendah yaitu 4,69\%, dan sampel nomor 1 (15 gram ampas teh dengan 10 gram lem kanji) memiliki nilai kadar air tertinggi yaitu 6,53\%. Nilai kadar air yang didapatkan sebenarnya bisa lebih rendah lagi, namun dikarenakan keterbatasan waktu yang tidak memungkinkan untuk melakukan pengujian sesuai dengan prosedur sehingga hasil yang didapatkan kurang optimal. Namun semua sampel memiliki nilai kadar air yang sesuai dengan standar mutu briket (SNI 01-62352000) yaitu $\leq 8 \%$.

Kandungan kadar abu (ash content) sebaiknya memiliki nilai yang rendah, kaitannya adalah jika kadar abu memiliki

Tabel 1. Uji Kadar Air (Moisture Content)

\begin{tabular}{cc}
\hline Sampel & Kadar Air (\%) \\
\hline Sampel 1 & 6,53 \\
Sampel 2 & 5,99 \\
Sampel 3 & 4,96 \\
Sampel 4 & 4,69 \\
\hline
\end{tabular}

Tabel 2. Uji Kadar Abu (Ash Content)

\begin{tabular}{cccc}
\hline \multirow{2}{*}{ Sampel } & \multicolumn{2}{c}{ Pengujian (\%) } & \\
\cline { 2 - 3 } & Simplo & Duplo & $\begin{array}{c} \\
\text { Rata- } \\
\text { rata (\%) }\end{array}$ \\
\hline Sampel 1 & 2,6 & 2,7 & 2,6 \\
Sampel 2 & 2,7 & 2,8 & 2,7 \\
Sampel 3 & 2,1 & 2,1 & 2,1 \\
Sampel 4 & 2,5 & 2,5 & 2,5 \\
\hline
\end{tabular}

Tabel 3. Uji Nilai Kalor

\begin{tabular}{cccc}
\hline Sampel & $\begin{array}{c}\text { Simplo } \\
\text { (cal/g) }\end{array}$ & $\begin{array}{c}\text { Duplo } \\
\text { (cal/g) }\end{array}$ & $\begin{array}{c}\text { Rata- } \\
\text { rata } \\
\text { (cal/g) }\end{array}$ \\
\hline Sampel 1 & 3958,79 & 3962,58 & 3960,69 \\
Sampel 2 & 3864,64 & 3904,22 & 3884,43 \\
Sampel 3 & 3337,4 & 3203,95 & 3270,68 \\
Sampel 4 & 3511,85 & 3579,23 & 3545,54 \\
\hline
\end{tabular}


nilai yang tinggi maka pengotornya juga banyak dan mempengaruhi kualitas udara disekitar ketika sedang melakukan pembakaran briket ampas teh, sedangkan kadar abu yang rendah dapat mengurangi tingkat pengotor udara pada proses pemanasannya. Hasil pengujian pada Tabel 2 menunjukkan sampel nomor 2 (15 gram ampas teh dengan 15 gram lem kanji) memiliki nilai kadar abu tertinggi yaitu 2,7\% dan sampel nomor 3 (20 gram ampas teh dengan 10 gram lem kanji) memiliki nilai kadar abu terendah yaitu 2,1\%. Sehingga semua persentase kadar abu yang terdapat dalam masing-masing sampel telah memenuhi standar mutu briket (SNI 016235-2000) yaitu $\leq 8 \%$.

Nilai kalor briket sangat berpengaruh pada efisiensi pembakaran briket. Makin tinggi nilai kalori briket makin bagus kualitas briket tersebut karena efisiensi pembakarannya tinggi. Dari hasil pengujian seperti yang ditunjukkan pada Tabel 3, terlihat jika dibandingkan dengan nilai baku mutu (SNI 01-6235-2000) memang tidak memenuhi kriteria karena semua dibawah $5000 \mathrm{cal} / \mathrm{g}$. Namun jika dibandingkan dengan hasil penelitian dengan bahan baku yang karakteristiknya hampir sama dengan ampas teh nilai kalor tersebut hampir sama, seperti jika dibandingkan dengan nilai kalor optimal sekam padi sebesar 3300,45 cal/g yang masih lebih kecil dari nilai kalor ampas teh. Nilai kalor yang paling baik yaitu sampel nomor 1 (15 gram ampas teh dengan 10 gram lem kanji). Sedangkan nilai kalor terendah yaitu sampel nomor 3 (20 gram ampas teh dengan 10 gram lem kanji) yaitu sebesar 3270,68 $\mathrm{cal} / \mathrm{g}$.

\section{KESIMPULAN}

Dari hasil penelitian ini dapat disimpulkan, yaitu ampas teh dapat dijadikan sebagai bahan penyusun utama pembuatan briket. Selain itu dapat disimpulkan bahwa yang memiliki kadar air yang paling rendah adalah sampel ke-4 sebesar 4,69\%, untuk kadar abu yang terendah adalah sampel ke-3 sebesar 2,1\% dan semua memenuhi standar baku mutu (SNI 01-6235-2000). Untuk hasil uji bom kalori memang tidak ada yang sesuai dengan (SNI 01-6235-2000) namun hasil yang hampir mendekati adalah sampel ke-1 sebesar 3960,69 cal/g namun jika dibandingkan dengan sekam padi dan beberapa komponen lain, ampas teh masih memiliki nilai kalor yang lebih tinggi. Briket ampas teh memiliki daya bakar yang cukup lama dan minim asap. Briket ampas teh dapat dijadikan alternatif bahan bakar dan proses pembuatan yang mudah dengan alat yang sederhana.

\section{Saran}

Berdasarkan hasil penelitian yang telah disimpulkan di atas, terdapat beberapa saran sebagai berikut, penelitian ini harus dikembangkan misalkan dengan menggunakan mesin untuk proses pencampuran antara lem dan ampas teh serta proses pengepresan bisa menggunakan briquetting machine. Sebaiknya diadakan pengujian kadar emisi yang dihasilkan, agar diketahui secara spesifik gas buangan yang tidak baik yang terdapat di dalam briket ampas teh. Harus dilakukan lagi pengembangan variasi antar ampas teh dan lem kanji agar mendapatkan komposisi yang lebih sempurna, sehingga briket dapat langsung dibakar tidak membutuhkan waktu yang lama. Dapat dikembangkan lagi pada penggunaan perekat, yang menggunakan bahan alam yang memiliki daya rekat kuat seperti getah dari buah nangka atau dari pohon jarak. 


\section{DAFTAR PUSTAKA}

[1] Agustian Tatogo. (2010) Pemanfaatan Serbuk Gergaji Kayu Menjadi Briket. Nabire Papua : SMK YPPK Adhi Luhur Kolese Le Cocq d'Armandville.

[2] Ahmad R.F, et al. (2015) Pemanfaatan Sekam Padi dan Limbah Teh Sebagai Bahan Briket Arang dengan Perekat Tetes Tebu. Sumatera Utara : Fakultas Pertanian, Universitas Sumatera Utara.

[3] Ainur Rizky, et al. (2015) Makalah Energi Terbarukan Briket Tempurung Kelapa. Bangkalan : Fakultas Teknik, Universitas Trunojoyo.

[4] Andasuryani, Renny, E.P. (2017) Studi Mutu Briket Arang dengan Bahan Baku Limbah Biomassa. Padang : Fakultas Teknologi Pertanian, Universitas Andalas.

[5] Anwari, F, et al. (2015) Pemanfaatan Tongkol Jagung dan Limbah Teh Sebagai Bahan Briket. Medan : Fakultas Pertanian, Universitas Sumatera Utara.

[6] Arief Chaeriawan. (2016) Pembuatan Briket Karbon dari Campuran Ampas Tebu dan Jerami Padi. Bogor : Fakultas MIPA, Institut Pertanian Bogor.

[7] Betari Saraswati, et al. (2013) Potensi dan Pengembangan Biomassa di Indonesia. Surabaya : Fakultas Teknik, Institut Teknologi Sepuluh November.

[8] Budhi, I., Agung, F., Harlatun, N. (2017) Pembuatan dan Karakterisasi Briket Bahan Bakar dari Ampas Tahu Sebagai Alternatif. Jurnal Ilmiah Teknik Kimia. Vol. 2 (1). Hal 1-7. Universitas Pamulang.

[9] Dimas, P.B. (2014) Laporan Praktikum Biokimia Analisis Kadar Air dan Kadar Abu. Semarang : Fakultas Perikanan dan Kelautan, Universitas Diponegoro.
[10] Puji, F., Alim. (2014) Optimasi Operasi Pirolisis Sekam Padi untuk Menghasilkan Bahan Bakar Bioarang Sebagai Bahan Bakar Alternatif. Semarang : Fakultas Teknik, Universitas Diponegoro.

[11] Yahya Agung. (1992) Pemanfaatan Ampas Teh dari Industri Teh Botol Sebagai Bahan Baku Pembuatan Papan Partikel. Bogor : Fakultas Teknologi Pertanian, Institut Pertanian Bogor.

[12] Yuli Ristianingsih, et al. (2013) Pembuatan Briket Bioarang Berbahan Baku Sampah Organik Daun Ketapang Sebagai Energi Alternatif. Banjarmasin : Fakultas Teknik, Universitas Lambung Mangkurat.

[13] https://www.google.com/search?q=alat +bom+kalorimeter\&safe=strict\&source $=$ lnms\&tbm=isch\&sa $=$ X\&ved $=0$ ahUK Ewidl76Kx6_fAhXKuI8KHVB1BFUQ _AUIDigB\&biw=1366\&bih=657\#img dii=G93H1Hj8hS8g2M:\&imgrc=uVD Q1_LeJda_jM:

[14] https://www.google.com/search?q=brik et + kompak\&safe $=$ strict \& source $=$ lnms \&tbm $=i s c h \& s a=X \& s q i=2 \& v e d=0 a h U$ KEwjNyr3Z27DfAhVjLH0KHdtACDo Q_AUIDigB\&biw=1366\&bih=657\#im grc $=$ knbxUBWRokrV_M:

[15] https://www.google.com/search?q=lem + kanji\&safe=strict\&source $=$ lnms\&tbm $=$ isch\&sa $=X \&$ sqi $=2 \& v e d=0$ ahUKEwjh vJWr27DfAhWo6YMKHU0mDk4Q AUIDigB\&biw=1366\&bih=657\#imgrc =AVca291itnNxnM:

[16] https://www.google.com/search?q=pen gujian+kadar+abu+dengan+tanur\&safe =strict\&source $=$ lnms\&tbm $=$ isch\&sa $=X$ \&ved=0ahUKEwiKxemX3LDfAhUG3 o8KHdJeBlkQ_AUIDigB\&biw=1366 \&bih=657\#imgrc=1AtX1rvp1x3uKM 